\title{
Evolving imprinting control regions: KRAB zinc fingers hold the key
}

\author{
Aimee M. Juan and Marisa S. Bartolomei \\ Epigenetics Institute, Department of Cell and Developmental Biology, Perelman School of Medicine, University of Pennsylvania, \\ Philadelphia, Pennsylvania 19104, USA
}

The monoallelic parent of origin-specific expression of imprinted genes in mammals is regulated by differentially DNA methylated imprinting control regions (ICRs). In contrast to most of the genome, ICRs must maintain their DNA methylation and parental identity despite extensive epigenetic reprogramming that takes place after fertilization. Previous work demonstrated that the Krüppelassociated box (KRAB)-containing zinc finger protein (KZFP) ZFP57 protects select ICRs from demethylation and preserves parental identity. However, some loci are unaffected in Zfp57-null mice. Thus, it has been speculated that other KZFPs must be involved in this process. Takahashi and colleagues (pp. 49-54) now report one such KZFP: ZFP445.

The differentially methylated imprinting control regions (ICRs) of imprinted genes (genes expressed in a monoallelic parent of origin-specific manner) pose a unique problem in mammalian development. ICRs must maintain their DNA methylation and parental identity after fertilization despite extensive epigenetic reprogramming that takes place as the gamete-supplied parental genomes regain pluripotency (Smith et al. 2012; Barlow and Bartolomei 2014). Previously, Li et al. (2008) showed that the Krüppel-associated box (KRAB)-containing zinc finger protein (KZFP) ZFP57 binds to methylated ICRs in preimplantation development, protecting them from demethylation and preserving parental identity. Nevertheless, although essentially all ICRs have the binding sequence for ZFP57, not all imprinted loci are affected in mice lacking Zfp57 (Li et al. 2008; Quenneville et al. 2011; Takahashi et al. 2015). For example, the ICRs at the H19/Igf2 and Igf2r/Airn loci are unaffected in Zfp57-null mice. Thus, it has been speculated that other KZFPs must be involved in this process. Here Takahashi et al. (2019) identify one such KZFP: ZFP445.

Using a human KZFP ChIP-exo (chromatin immunoprecipitation with exonuclease digestion) database (Imbe-

[Keywords: KRAB zinc finger proteins; ZFP445; ZFP57; genomic imprint maintenance; resistance to epigenetic reprogramming] Corresponding author: bartolom@pennmedicine.upenn.edu Article is online at http://www.genesdev.org/cgi/doi/10.1101/gad.322990. 118 . ault et al. 2017), Takahashi et al. (2019) found ZFP445 enriched at eight out of 17 ICRs in human embryonic stem cells (hESCs), which also overlapped with ZFP57 and KAP1 binding. They confirmed that the mouse ortholog binds methylated ICRs in hybrid mouse ESCs (mESCs) and colocalized with ZFP57 and KAP1. Interestingly, maternal and zygotic deletion of Zfp445 in mouse embryos did not affect either ICR methylation or imprinted gene expression. Takahashi et al. (2019) postulated that Zfp57 might compensate for loss of $Z f p 445$, suggesting that these two proteins cooperate to maintain mouse imprints in vivo. To test this hypothesis, the investigators generated a series of complex alleles. Homozygous zygotic mutations for both $Z f p 445$ and $Z f p 57$ gave rise to a much more dramatic phenotype than either Zfp 445 or Zfp $57 \mathrm{mu}$ tations alone. Embryos were severely growth-restricted and died prenatally with complete loss of DNA methylation at 14 out of 19 ICRs tested, including the historically immune H19 ICR. Because some loci were still variably affected by the mutations, Takahashi et al. (2019) used an elegant breeding scheme to eliminate maternal $Z f p 57$ in the doubly null mice and demonstrated that four of the remaining five resistant ICRs were protected by maternal ZFP57 deposition (IG-DMR, Impact, Grb10, and KvDMR). As in other mutants, Peg10 remained unaffected. Unfortunately, because of embryonic lethality and current lack of a germline-specific mutation, only one embryo lacking maternal-zygotic forms of $Z f p 57$ and zygotic $Z f p 445$ could be analyzed. Nevertheless, these results indicate that $Z f p 445$ is likely compensating to preserve DNA methylation at unaffected ICRs in Zfp57 knockouts. Takahashi et al. (2019) conclude that murine ICRs depend on ZFP445 and ZFP57 to different degrees and that these KZFPs act together to maintain allele-specific imprints in early mouse development.

In contrast, the case in humans appears different. Humans, unlike mice, appear to be much less dependent on ZFP57. ZFP57 mutations in humans, which are associated with transient neonatal diabetes mellitus (TNDM)

(C) 2019 Juan and Bartolomei This article is distributed exclusively by Cold Spring Harbor Laboratory Press for the first six months after the full-issue publication date (see http://genesdev.cshlp.org/site/misc/ terms.xhtml). After six months, it is available under a Creative Commons License (Attribution-NonCommercial 4.0 International), as described at http://creativecommons.org/licenses/by-nc/4.0/. 


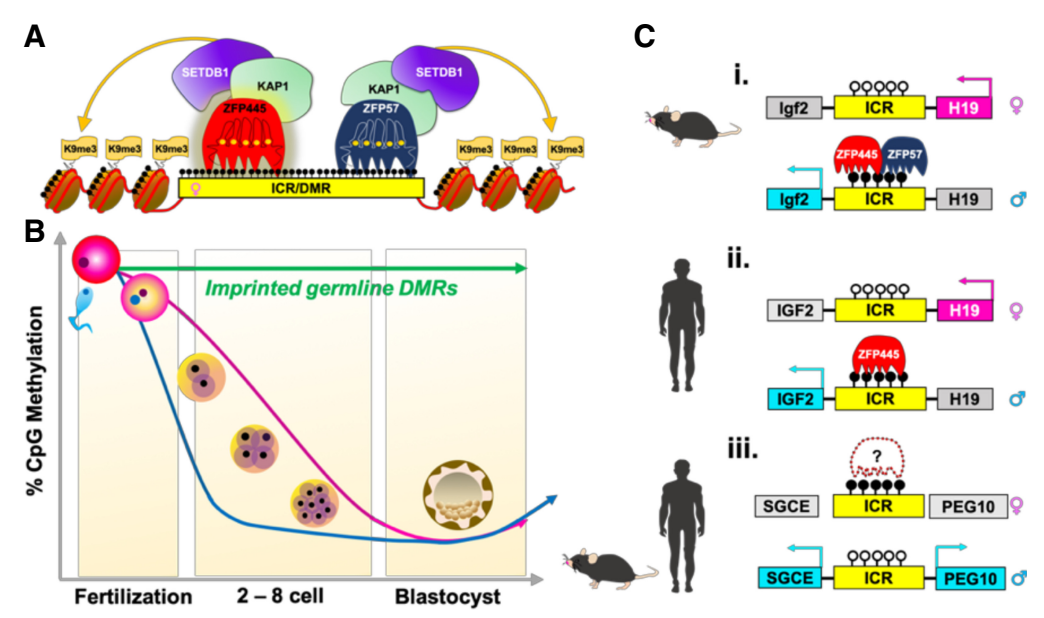

Figure 1. Model for ZFP57 and ZFP445-KAP1-mediated regulation of genomic imprints in the post-fertilization embryo. (A) An example of a maternally silenced imprinted gene. ZFP445 and ZFP57 bind to the methylated ICR (dark lollipops) and recruit scaffold protein KAP1 and histone methyltransferase SETDB1 to deposit H3K9me3 on the silenced allele (other components of the complex are not depicted for simplicity). (B) Shortly after fertilization, the highly specialized genomes of the gametes are demethylated to produce a totipotent zygote or blastocyst. (Pink line) Maternal genome; (blue line) paternal genome. Imprinted ICRs/germline differentially methylated regions (DMRs) are protected from this wave of DNA demethylation (green line) to maintain parental allele-specific methylation. (C) ZFP57 and ZFP445 protect ICRs from post-fertilization DNA demethylation in a species- and ICR-specific manner. In rodents, ZFP57 and ZFP445 may cooperate to preserve $H 19$ imprints (panel i), while, in humans, ZFP445 alone appears sufficient (panel ii). (Panel iii) In both species, PEG10/Peg10 was not regulated by either ZFP57 or ZFP445, suggesting that a different KZFP is involved.

(Mackay et al. 2008), are compatible with life and lead to hypomethylation of only a few ICRs. ZFP57 is not detected prior to the eight-cell stage, whereas ZFP445 is highly expressed. Using hESCs as a model for the postfertilization embryo, Takahashi et al. (2019) show that shRNA knockdown of ZFP445 resulted in a significant loss of KAP1 binding and H3K9me3 at multiple ICRs, increased gene expression, and loss of ICR methylation, including at the $H 19$ locus. These findings suggest that, similar to ZFP57, ZFP445 binds to human ICRs and recruits KAP1 to trigger the deposition of $\mathrm{H} 3 \mathrm{~K} 9 \mathrm{me} 3$ (Fig. 1A). Although ZFP445 harbors the classic KRAB sequence, Takahashi et al. (2019) were unable to determine whether ZFP445 binds KAP1 directly. Thus, unlike in mice, ZFP445 alone appears necessary to preserve ICR imprints and regulate gene expression of a subset of human imprinted genes, particularly H19 (Fig. 1C, panels i,ii).

Because ZFP445 cooperates with ZFP57 in mice but not humans, Takahashi et al. (2019) investigated the conservation of these proteins throughout mammalian evolution. They identified ZFP445 orthologs in marsupials, indicating that ZFP445 evolved before ZFP57 to maintain imprints. In humans, ZFP445 has a much lower mutational tolerance than ZFP57. Therefore, mutations in ZFP445 may cause severe loss of imprinting at many loci, which would be detrimental to human health. Takahashi et al. (2019) emphasize that PEG10, an ancient imprinted gene present in marsupials, does not appear to be regulated by ZFP445 or ZFP57. PEG10 shares homology with the sushi-ichi family of retrotransposons and evolved during mammalian viviparity as an essential placental gene (Suzuki et al. 2007). Given that KZFPs and cytosine methylation are major mechanisms for the silencing of retroelements, it is likely that the PEG10 ICR retains this type of regulation by a different KZFP (Fig. 1C, panel iii.)

Importantly, these results underscore the concept that genomic imprinting is not a "one size fits all" phenomenon. This is not entirely surprising because ICRs diverge at the level of sequence, size, genic location, and func- tion other than conferring allelic identity. The data suggest that as imprinted genes evolved across species, ICRs had access to different genetic and protein material to confer DNA methylation maintenance. Nevertheless, the Zfp57/Zfp445-null mouse model suggests that the KZFPs can compensate for each other. Given that imprinted genes are essential for normal development, compensation or redundancy by KZFPs could be a protective mechanism for organism viability. As exemplified in patients with TNDM and Zfp57/Zfp445-null animals, one KZFP mutation will not impact all imprinted genes.

The discovery of ZFP445 suggests that additional ZFPs are involved. Still, the mechanism by which KZFPs influence imprinted domains remains to be determined. During post-fertilization reprogramming, do KZFP complexes inhibit active and passive DNA demethylation of the parental imprints, maintain ICR methylation, or both? Although Takahashi et al. (2019) confirm ZFP57/ZFP445induced heterochromatin at ICRs, the biochemistry underlying escape of imprints from demethylation is an open area of investigation. Moreover, it is unclear how these proteins specifically recognize the methylated targets at imprinted loci. The hexanucleotide motif for ZFP57 is enriched in repetitive sequences throughout the genome (Strogantsev et al. 2015), while the consensus sequence and chromatin state that specifies ZFP445 binding are undefined. Nonetheless, the data presented here begin to piece together the puzzle for a common mechanism that imprints use to preserve their DNA methylation in early embryogenesis.

\section{References}

Barlow DP, Bartolomei MS. 2014. Genomic imprinting in mammals. Cold Spring Harb Perspect Biol 6: a018382. doi: 10.1101/cshperspect.a018382

Imbeault M, Helleboid PY, Trono D. 2017. KRAB zinc-finger proteins contribute to the evolution of gene regulatory networks. Nature 543: 550-554. doi:10.1038/nature21683 
Li X, Mitsuteru I, Zhuo F, Youngson N, Zuo Z, Leder P, FergusonSmith AC. 2008. A maternal-zygotic effect gene, Zfp57, maintains both maternal and paternal imprints. Dev Cell 15: 547-557. doi:10.1016/j.devcel.2008.08.014

Mackay DJG, Callaway JLA, Marks SM, White HE, Acerini CL, Boonen SE, Dayanikli P, Firth HV, Goodship JA, Haemers $\mathrm{AP}$, et al. 2008. Hypomethylation of multiple imprinted loci in individuals with transient neonatal diabetes is associated with mutations in ZFP57. Nat Genet 40: 949-951. doi: 10.1038/ng.187

Quenneville S, Verde G, Corsinotti A, Kapopoulou A, Jakobsson J, Offner S, Baglivo I, Pedone PV, Grimaldi G, Riccio A, et al. 2011. In embryonic stem cells, ZFP57/KAP1 recognize a methylated hexanucleotide to affect chromatin and DNA methylation of imprinting control regions. Mol Cell 44: 361372. doi:10.1016/j.molcel.2011.08.032

Smith ZD, Chan MM, Mikkelsen TS, Gu H, Gnirke A, Regev A, Meissner A. 2012. A unique regulatory phase of DNA methylation in the early mammalian embryo. Nature 484: 339-344. doi:10.1038/nature 10960
Strogantsev R, Krueger F, Yamazawa K, Shi H, Gould P, GoldmanRoberts M, McEwen K, Sun B, Pedersen R, Ferguson-Smith AC. 2015. Allele-specific binding of ZFP57 in the epigenetic regulation of imprinted and non-imprinted monoallelic expression. Genome Biol 16: 112. doi:10.1186/s13059-0150672-7

Suzuki S, Ono R, Narita T, Pask A, Shaw G, Wang C, Kohda T, Alsop A, Marshall-Graves JA, Kohara Y, et al. 2007. Retrotransposon silencing by DNA methylation can drive mammalian genomic imprinting. PLoS Genet 3: e55. doi:10.1371/ journal.pgen.0030055

Takahashi N, Gray D, Strogantsev R, Noon A, Delahaye C, Skarnes WC, Tate PH, Ferguson-Smith AC. 2015. ZFP57 and the targeted maintenance of postfertilization genomic imprints. Cold Spring Harb Symp Quant Biol 80: 177-187. doi:10.1101/sqb.2015.80.027466

Takahashi N, Coluccio A, Thorball CW, Planet E, Shi H, Offner S, Turelli P, Imbeault M, Ferguson-Smith AC, Trono D. 2019. ZNF445 is a primary regulator of genomic imprinting. Genes $\operatorname{Dev}$ (this issue). doi: 10.1101/gad.320069.118. 


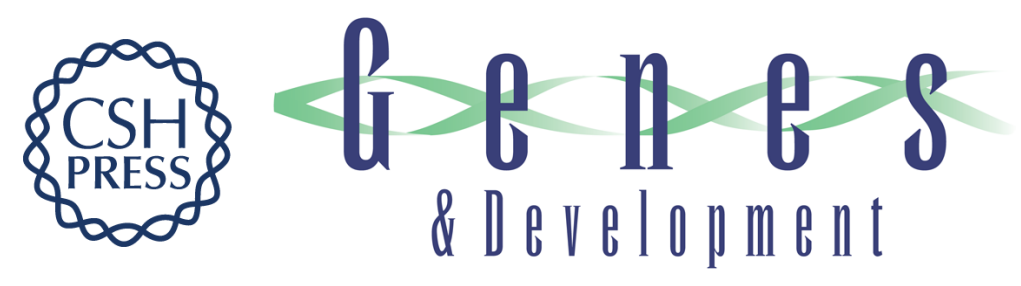

\title{
Evolving imprinting control regions: KRAB zinc fingers hold the key
}

\author{
Aimee M. Juan and Marisa S. Bartolomei
}

Genes Dev. 2019, 33:

Access the most recent version at doi:10.1101/gad.322990.118

\section{Related Content ZNF445 is a primary regulator of genomic imprinting \\ Nozomi Takahashi, Andrea Coluccio, Christian W. Thorball, et al. Genes Dev. January, 2019 33: 49-54}

References This article cites 10 articles, 2 of which can be accessed free at: http://genesdev.cshlp.org/content/33/1-2/1.full.html\#ref-list-1

Articles cited in: http://genesdev.cshlp.org/content/33/1-2/1.full.html\#related-urls

Creative This article is distributed exclusively by Cold Spring Harbor Laboratory Press for the first Commons License six months after the full-issue publication date (see http://genesdev.cshlp.org/site/misc/terms.xhtml). After six months, it is available under a Creative Commons License (Attribution-NonCommercial 4.0 International), as described at http://creativecommons.org/licenses/by-nc/4.0/.

Email Alerting Receive free email alerts when new articles cite this article - sign up in the box at the top right corner of the article or click here.

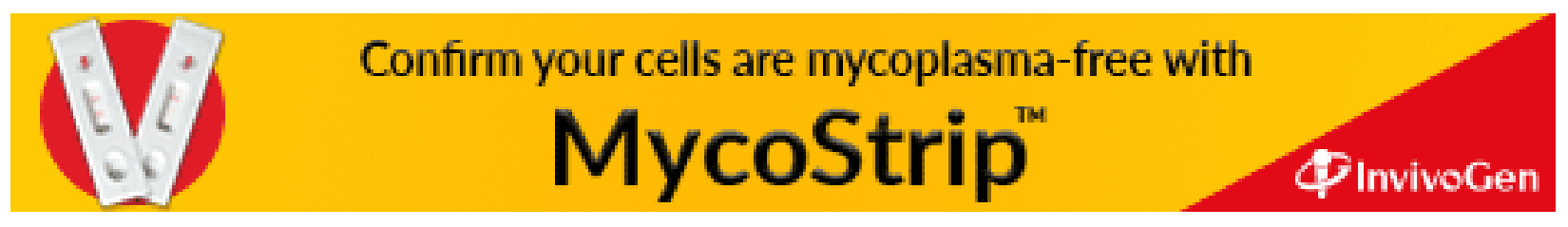

